eISSN: 2659-6482

DOI: https://doi.org/10.14201/pmrt.20667

\title{
LOVE ACTUALLY Y LAESFERA MUSICAL COMO CÓMPLICE DE LA PERPETUACIÓN DE LOS ROLES DE GÉNERO TRADICIONALES
}

\section{Love Actually and the Musical Sphere as an Accomplice to the Perpetuation of Traditional Gender Roles}

\author{
Beatriz HERNÁNDEZ POLO \\ Universidad de Salamanca \\ beahp@usal.es
}

RESUMEN: La comedia romántica sigue siendo a día de hoy uno de los géneros cinematográficos más demandados por la sociedad de consumo. A pesar de los numerosos ejemplos recientes en los que aparecen nuevos enfoques de género, prevalece el empoderamiento de la mujer o se visibiliza su ausencia, muchas de las comedias románticas que han copado la gran pantalla y han pasado a ser considerados clásicos del cine comercial, se cimientan en la perpetuación de los roles tradicionales. Este es precisamente el caso concreto de las tramas paralelas que se suceden en la película Love Actually (Reino Unido, 2003), dirigida por Richard Curtis, considerada una de las comedias románticas inglesas más populares de la historia y cuya banda sonora sería, además, proyectada como potente producto de ventas. Precisamente al respecto, el pasado mes de diciembre, catorce años después de su estreno, las redes sociales abrían un hilo de discusión donde proponían una visualización del filme desde una perspectiva feminista. A lo largo de nuestro artículo no solo estudiaremos los roles desempeñados por los personajes femeninos y masculinos, cuya caracterización perpetúa la imagen de la mujer entre otros como cuidadora, objeto sexual, madre, femme fatale y del hombre como ente poderoso, culto y naturalmente infiel, sino que nos centraremos en qué elementos constituyen el envoltorio atractivo que logra convertir una trama sustentada en unos principios claramente desigualitarios en una candorosa pieza cinematográfica que 
persigue ser una oda al amor en todas sus modalidades. En este proceso, como veremos, junto al ambicioso reparto de actores o el recurso del humor, la música actuará como cómplice y eje principal en el desarrollo de las diferentes tramas sustentando la caracterización de roles y como adalid de las principales escenas de la película.

Palabras clave: género; roles; comedia; música; banda sonora; estereotipos.

ABSTRACT: The romantic comedy remains today as one of the most demanded film genres by the consumer society. In spite of the numerous and recent examples in which we can find a new gender approach, where the empowerment of women prevails or their absence is visible, most of the romantic comedies that have reached the big screen and have been considered classics of commercial cinema, are based on the perpetuation of traditional roles. This is precisely the case of the parallel plots that occur in the movie Love Actually (United Kingdom, 2003), directed by Richard Curtis, considered one of the most popular English romantic comedies developed in Christmas and whose soundtrack would be, also, projected as a powerful sales product. Last December, fourteen years after its Premiere, social networks opened a chain of discussion where they proposed the visualization of the film from a feminist perspective. Throughout our article we won't only study the roles played by the female and male characters, whose characterization perpetuates the image of the woman, among others, as caregiver, sexual object, mother, femme fatale, meanwhile men are projected as powerful, cultured and unfaithful, but we will focus on those elements which constitute the attractive package that manages to convert a plot based on clearly unequal principles in a candid cinematographic piece that pursue being a poem of love in all its forms. In this process, as we will see throughout the text, along with the ambitious distribution of the group of actors and the use of the sense of humor, music will act as an accomplice and main object in the development of the different plots, supporting with the characterization of roles and as a key ingredient of main scenes of the movie.

Keywords: Genre; roles; comedy; music; soundtrack; stereotypes.

En las corrientes de la nueva musicología que comienzan a manifestarse en la década de los ochenta en Estados Unidos, la visión posmodernista y relativista iría poco a poco imponiéndose frente a la perspectiva etnocéntrica y hegemónica 
que tendría como testigo y referente de la Historia al hombre blanco, occidental, heterosexual y de clase media-alta. En esta corriente comenzaría a abrirse paso una musicología que apostaría por la visualización de los grupos sociales que habían sido obviados en los dogmas y el trazado de la historia, entre ellos, las personas de diferente raza, lo no occidental, el colectivo LGTBI, las personas procedentes de los contextos más desfavorecidos y también las mujeres. Ahora bien, la investigación actual no duda de que la nueva historia pasa por deconstruir los conceptos y discursos hegemónicos que han prevalecido hasta casi el presente y repensarlos desde una perspectiva crítica y abierta, que además ponga de manifiesto las situaciones de injusticia y desigualdad que han experimentado determinados sectores como los aludidos anteriormente. Y en consecuencia, la evolución, la reconstrucción de la historia en todas sus dimensiones pasa por la mirada a mayorías y minorías, a todas las dimensiones geográficas, económicas, políticas, sociales y culturales y necesariamente va de la mano con una reeducación social en la que todavía nos hallamos inmersos.

Por otro lado el cine, como producción artística y cultural, constituye indudablemente una herramienta que ofrece la posibilidad de que la sociedad pueda conocer y repensar los procesos históricos, sociales y culturales del pasado y del presente desde una nueva dimensión y a través de los ojos de guionistas, directores y productores. De ahí la proliferación de biopics y de guiones inspirados en historias o situaciones reales que persiguen acercarnos a épocas, contextos o fenómenos como la segregación racial o la sexualidad a través de personajes con los que poder empatizar, como por ejemplo sucede en algunas de las últimas películas nominadas a los premios Óscar, Moonlight (2017), Green Book (2018) o The Favourite (2018). Sin embargo, frente al género de un cine social o, al menos, con motivación social, que de una u otra forma pretende concienciar al público ante situaciones reales inspiradas en la problemática que se viven, se han vivido o que podrían vivirse, tenemos una cartelera de cine comercial que, en una gran proporción, todavía a día de hoy sigue siendo objeto de crítica por el número y la forma en la que se proyecta la mujer y la feminidad.

En los últimos años estamos asistiendo a un escenario reivindicativo donde empieza a denunciarse la masculinizada industria del cine, solicitando una presencia más activa de la mujer tanto delante como detrás de las cámaras. Gracias a plataformas como el \#MeToo, que tendría notoria presencia en la industria de Hollywood, o a la sororidad que se ha manifestado entre las mujeres víctimas directas e indirectas de la inequidad, la sociedad europea cada vez está más concienciada acerca de esta problemática social y de la, aún hoy, masculinizada industria del cine (Brown, 2017). De este modo, son numerosas las muestras cinematográficas que en los últimos años visibilizan las injusticias y los derechos de las mujeres, tales como Figuras ocultas (Hidden Figures, Estados Unidos, 2016), Big eyes (Estados 
BEATRIZ HERNÁNDEZ POLO

LOVE ACTUALLY Y LA ESFERA MUSICAL COMO CÓMPLICE DE LA PERPETUACIÓN DE LOS ROLES DE GÉNERO TRADICIONALES

Unidos, 2014), Collette, (Reino Unido, 2018) Carol (Reino Unido, 2015), La fuente de las mujeres (La Source des femmes, Bélgica, 2011), Mustang (Francia, 2015), Sufragistas (Suffragette, Reino Unido, 2015), Una cuestión de género, (On the Basis of Sex, Estados Unidos, 2018) o Tres anuncios en las afueras (Three Billboards Outside Ebbing, Missouri, Reino Unido, 2017). En definitiva, múltiples ejemplos llegan a la gran pantalla logrando visibilizar y cooperar en el empoderamiento de la mujer, hacer frente al techo de cristal y denunciar situaciones que fueron decisivas en este proceso a lo largo de la historia. Al margen de otros ejemplos de las, cada vez más, películas que narran y visibilizan historias de mujeres, de todas las culturas, facetas y que apuestan por su empoderamiento y el cuestionamiento del patriarcado, llama poderosamente la atención la presencia periódica de una comedia romántica que se ha convertido en un clásico navideño, Love Actually.

A pesar de los numerosos años transcurridos desde el estreno de Love Actually (Reino Unido, 2003), no ha sido hasta tiempos recientes cuando, a raíz de las progresivas movilizaciones que culminarían en el 8 de marzo de 2018 y al consiguiente impulso en la concienciación a nivel nacional en torno a los roles de género, cuando público y crítica parecen haber reparado en la distribución desigualitaria de los roles y tramas proponiendo la visualización del filme desde una perspectiva de género que hasta el momento había sido obviada (Filardi, 2017). En ese sentido, si bien, por un lado nos preguntamos cuáles han podido ser las razones por las que durante quince años la cinta se haya convertido en un clásico que sigue año tras año formando parte indiscutible de la parrilla televisiva en las festividades navideñas y que haya prevalecido la visualización irreflexiva aderezada por las tramas y el amor, a la mirada crítica desde una perspectiva de género, por otro, trataremos de ir más allá. Y es que, no solo pretendemos limitarnos a poner de manifiesto la perpetuación de los roles tradicionales que se trazan en la cinta, sino que, más concretamente, trataremos de imbuirnos en el papel que desempeña la música en el desarrollo, enfatización o la confección de estos roles de género tradicionales que, como veremos prevalecen a lo largo del largometraje.

Love Actually es una película con guion original ambientada en el momento de su producción, donde se acusa que incluso Tony Blair, primer ministro inglés entre 1998 y 2007, tendría un gran parecido con el actor Hugh Grant. Con esto nos proponemos matizar que la película en particular, como cualquier otra producción artística, debe ser entendida dentro de su contexto de creación para poder extrapolar hipótesis y conclusiones. De este modo, nadie duda de que la película refleja la realidad en torno a género que se vivía en el año 2003, en este caso, en la sociedad de Reino Unido, la cual, históricamente, se caracteriza por su férreo apego a las tradiciones y donde a pesar del cosmopolitismo vigente en muchos de sus núcleos urbanos y del peso de la figura monárquica, hoy día mujer, los pilares de la sociedad han sido conservadores con gran presencia masculina 
(Ashby, 2005). Así, en palabras de Olivia Hetreed, guionista y escritora inglesa, en la actualidad y precisamente desde 2003 , presidenta de la principal asociación de guionistas de Reino Unido, la Writers' Guild of Great Britain (WGGB), el cine actual todavía «no sirve como muestra de la realidad», dado que las historias que cuenta son eminentemente masculinas, así mismo, pone de manifiesto que pese a que en Reino Unido hay mujeres creadoras y público potencial para consumir estas producciones, la toma de decisiones en torno a la industria del cine inglés sigue estando en manos de los hombres (Belinchón, 2017).

A priori, Love Actually como historia coral, en la que se reúnen múltiples tramas, trata de hacer un recorrido por el amor en todas sus manifestaciones humanas. Entre personas de diferente raza, escalafón social, formación académica, entre padres e hijos, entre hermanos, en matrimonios jóvenes, matrimonios maduros, entre amigos, abarcando además temas anejos como la infidelidad, la viudedad o la sexualidad. La película de nacionalidad inglesa, de en torno a dos horas de duración, sería dirigida por Richard Curtis, quien se estrenaba como director tras haber participado como guionista de cintas como Four Weddings and a Funeral o Notting Hill y sería proyectada con gran éxito en taquilla en las navidades del 2003. Catalogada como drama, comedia y romance, cuenta con un reparto de actores espectacular, entre los que podemos mencionar a Emma Thompson, Liam Neeson, Alan Rinkman, Keyra Knightley, Mr. Bean (Rowan Atkinson), Colin Firth, Hugh Grant, Laura Linney y Claudia Schiffer, entre otros, que sin duda contribuiría indudablemente a su rotundo éxito en taquilla. Por su parte, la banda sonora, publicada también en 2003, cuenta con dieciocho pistas y se convertiría también en un producto de ventas, donde la música forma parte inherente de unas tramas muy jugosas para un análisis de género. Craig Armstrong (Glasgow, 1959), por su parte, será el encargado de coordinar una banda sonora que prácticamente no deja de sonar en ningún momento y que integra música preexistente en su versión original, música preexistente versionada y original, y tres temas de música original incidental compuestos por el propio Armstrong. En total diecisiete temas que serían comercializados bajo el título Love Actually: Original Motion Picture Soundtrack (2003).

Si hacemos un fugaz repaso por los personajes, entre los papeles femeninos tenemos a una mujer madura casada y madre de dos hijos víctima de la infidelidad de su marido, a una mujer que ha asumido el rol de cuidar a su hermano con un trastorno psiquiátrico grave, a una niña popular que canta en un grupo del colegio, a una mujer joven que trabaja como secretaria y que seduce a un hombre casado, a una asistente personal del Primer Ministro inglés en Downing Street, procedente de una clase social media-baja, a una mujer portuguesa del ámbito rural, que entra a trabajar como asistenta de hogar en la casa temporal de un escritor inglés, y por último, a una mujer joven, cuya única información de la que disponemos en el 
momento de la trama es su papel como novia en la boda que se celebra. Por otro lado, en los papeles masculinos nos encontramos con un hombre maduro casado y directivo de una empresa que es seducido por su secretaria, un Primer Ministro Inglés, un escritor, hombre culto que es víctima de un desengaño amoroso y se traslada a una villa del sur de Francia donde precisa la ayuda de una asistente de hogar, un joven perceptiblemente sensible y detallista, amigo del marido de la chica de la que está enamorado en secreto, un hombre viudo, un niño impopular que se propone captar la atención de la chica más popular del colegio y por último, una vieja gloria del rock que trata de recuperar su popularidad mediante la grabación de un bit navideño. En definitiva, políticos, intelectuales, directivos o artistas, con solvencia económica y posiciones influyentes llaman la atención frente a mujeres que ejercen únicamente como madres, amas de casa, asistentes y secretarias, subordinadas al sector masculino. A continuación, pasaremos a repasar brevemente algunas de las subtramas, con objeto de situar a los personajes y el papel que ejerce la música en la confección de los roles de género tradicionales que se reflejan a lo largo del largometraje.

El primer ejemplo que nos proponemos analizar es la historia protagonizada por Karen y Harry, un matrimonio convencional, maduro y con hijos. Karen, representada por Emma Thompson, se perfila como una madre paciente, empática, inteligente y volcada en la crianza de sus hijos que, en la mayor parte de las escenas, aparece dentro del hogar o llevando a cabo tareas vinculadas a su condición de madre o esposa y de la que no se menciona ningún vínculo profesional. Por su parte Harry, representado por Alan Rickman, es directivo de una empresa, con lo que se matiza una vida laboral ajena al entorno doméstico, en la que se plantea una relación extramatrimonial con una joven subordinada, secretaria de su oficina. El personaje en discordia de la trama es Mia, interpretada por Heike Makatsch, que aparece caracterizada como una femme fatale que supone una tentación para la debilidad de Harry, con corte de pelo estilo bob de los años veinte, signo de la mujer liberada y pigmentos rojo intenso en sus labios (Clément, 1988).

En la trama, la música sale a colación en el momento clave en que Karen descubre la posible infidelidad de su marido cuando, en lugar del cordón de oro y el colgante en forma de corazón que había descubierto de manera accidental, bajo el árbol encuentra un disco de Joni Mitchel con una nota aneja en la que Harry le señala «para que siga cultivando su educación sensitiva». En la escena que sigue aparece la música diegética cuando Karen, consciente de la humillación, llora mientras escucha sola, en el reproductor de su habitación, el tema «Both Sides Now» del disco que acaba de recibir, aunque después simula normalidad para asistir en familia a la función navideña del colegio. El tema potencia el sabor amargo de la escena y matiza el mensaje de las «dos caras» de su propio marido que acaba de descubrir. Sin embargo, al mismo tiempo se ponen de manifiesto también las dos 
caras de la infidelidad, la mujer humillada y la mujer culpabilizada, alternándose en la misma secuencia, las imágenes de Karen, llorando en su dormitorio, y las de Mia, en su propia casa, en ropa interior, independiente, satisfecha con la consecución del colgante, su capricho y su objetivo.

Podríamos pensar que el cedé de Joni Mitchel junto al mensaje constituye un obsequio menos superficial, y sentimentalmente más valioso, máxime cuando en la compra del colgante, en la que Mr. Bean ejerce como vendedor, Harry muestra un ostensible desinterés. En ese sentido, su imagen, que a lo largo de la cinta aparece fortalecida como jefe y como padre, tampoco se ve excesivamente deteriorada como esposo. Sin embargo, curiosamente será el hecho de que el regalo sea un cedé y no una joya lo que lleva a Karen a sentirse desolada. Pero ¿qué lectura debemos hacer de ello? ¿Se trata solo de descubrir un regalo para una tercera persona o la dureza radica también en la conciencia del paso del tiempo y la pérdida del rol de mujer bella y deseada en la madurez?

En nuestra opinión, el planteamiento subyacente de toda esta secuencia gira explícitamente en torno a la belleza y al atractivo físico. El desarrollo de la misma, aderezada con el tema de «Both Sides», pasa por mostrar primeros planos y planos tres cuartos del cuerpo de las dos mujeres protagonistas, realzando por un lado el sobrepeso, el vestuario clásico y abultado de Karen al tiempo que proyectan el cuerpo de Mia en ropa interior y con el colgante. Se presenta así a la mujer humillada y se contrapone a la mujer responsable de la infidelidad, la mujer arpía que por su propia ambición y codicia es capaz de seducir a un padre de familia. Se la culpabiliza y señala incluso con el disfraz diablesco con el que Mia asiste a la fiesta de Navidad de la empresa, en la cual Karen, también presente, la descubre bailando con su marido. En este nuevo ejemplo de música diegética, cómplice de la infidelidad, termina con la advertencia de Karen a su marido del peligro de acercarse a una mujer así, lo que contribuye a proyectar una vez más que la actuación de Mia es un acto de maldad, mientras que la de Harry lo es de debilidad.

Otra de las subtramas es la protagonizada por Juliet, personaje interpretado por Keira Knightley. En ella se narra la boda entre ella y Peter, interpretado por Chiwetel Ejiofor. Uno de los momentos más populares del filme será la boda en la que Mark, interpretado por Andrew Lincoln, el mejor amigo del novio que está silenciosamente enamorado de Juliet, les ha preparado una sorpresa a la pareja contrayente con una interpretación en directo de una versión de All you need is love, de The Beatles, en la que los diversos ejecutantes se levantan y aparecen por los diferentes rincones de la iglesia. Teniendo en cuenta que el matrimonio es entre un hombre negro y una mujer blanca, la cuestión racial resulta ciertamente significativa. En ese sentido, nos detendremos brevemente a analizar quién participa en el aderezo musical de la boda, que entrelaza la popular marcha nupcial de Félix Mendelssohn con el comienzo de la Marsellesa que marca el inicio del clásico de 
The Beatles, interpretados por el organista, un hombre blanco. En primer lugar, arriba en el coro aparecen dos pequeños conjuntos vocales formados por mujeres y hombres negros y blancos y entre ellos un cantante solista de raza negra, interpretado por el cantante de soul Lynden David Hall, fallecido en 2006, pocos años después del rodaje. Después se suma el cuarteto clásico, formado por dos hombres, violín primero y violonchelo y dos mujeres, violín segundo y viola. A continuación aparecen progresivamente los vientos entre los invitados, sentados en los bancos, entre los que ya no encontramos a ninguna mujer, sino únicamente hombres y en su gran mayoría blancos. En concreto, y por orden de aparición, tres trompetas interpretadas por tres hombres blancos, dos flautistas por dos hombres blancos, tres trombones por dos hombres blancos y un hombre negro y dos saxofones por un hombre negro y otro blanco. Y, por último, la intervención termina con un solo de guitarra eléctrica interpretado también por un hombre blanco. Únicamente aparecen dos hombres de raza negra que, concretamente, tocan el trombón y el saxofón. En definitiva, se vuelve de nuevo a recurrir a estereotipos tradicionales, normativos y etnocéntricos en cuestión de raza, género y música. Si bien por un lado se perpetúa el estereotipo de música clásica interpretada por personas de raza blanca, por su parte, las personas de raza negra figuran en papeles, bien ligados al góspel, como entre el coro en la boda y el solista de soul o bien al jazz, como el trombón y el saxofón. Y en lo que respecta a las mujeres, las encontramos como intérpretes vocalistas de góspel y únicamente nos topamos con instrumentistas de raza blanca, en concreto una intérprete de violín y otra de viola.

Volviendo a los protagonistas de la trama, sin lugar a dudas, el personaje central es Juliet, ya que tanto durante como después de la boda, su pareja desempeña un rol pasivo e intrascendente. No obstante, en ningún momento se proporcionan datos acerca de sus respectivas dedicaciones laborales, de forma que en la cinta parece ser una cuestión secundaria. Por el contrario, la única preocupación de Juliet en el momento de la trama gira en torno a su boda. Lo más importante en ese momento de su vida parece ser todo lo concerniente a la celebración. Se verá inmersa en un triángulo amoroso cuando decida acudir al mejor amigo de su novio en busca del registro videográfico y en concreto de buenos planos de su vestido. Tras la visualización del vídeo de la boda grabado por este, en el que únicamente aparecen planos suyos y ninguno de su marido, se dará cuenta de que el verdadero motivo por el que mantenía esa distancia aparentemente fría es que estaba enamorado de ella y al mismo tiempo se desmiente la homosexualidad sobre la que se hipotetiza en algunos diálogos. La música incidental seleccionada para la secuencia es "Glasgow Love Theme», una de las tres únicas partituras originales compuestas para el largometraje que enlaza con el tema de Dido, «Here with me», escogido para la escena en la que Mark sale a la calle al verse descubierto y se debate entre su lealtad a Peter y sus sentimientos hacia Juliet. En el desenlace de la historia Mark acude a casa de Juliet con una serie de carteles con texto y fotografías cuyos comentarios aluden esencialmente a cuestiones relacionadas 
con el aspecto físico y un reproductor musical que será cómplice de la trama, con voces blancas cantando villancicos en forma de aguinaldo para poder confesar sus sentimientos a Juliet sin la sospecha de Peter. Nos encontramos aquí con un sutil intento de superar estereotipos de raza y de sexualidad pero que sin embargo resulta en un papel muy poco significativo para el novio, y en el que nuevamente la pareja protagonista son mujer y hombre blanco.

En tercer lugar, tenemos la historia protagonizada por Colin Firth, escritor que tras descubrir la infidelidad de su esposa con su propio hermano decide marcharse a un pequeño pueblo del sur de Francia, localizado en un enclave rural idílico que aporta distancia contextual al ambiente navideño e invernal que se impone en el resto de las tramas. Durante su estancia, contará con los servicios de una joven portuguesa proveniente de una familia humilde y rural que asume las tareas de hogar mientras él escribe. No hablan el mismo idioma, ella le habla en portugués y él en inglés, por lo que la música incidental compuesta para esta trama, concretamente «Portuguese Love Theme», actúa como argamasa en el desarrollo de los diálogos infructuosos. La música trata de situar al espectador en el contexto campestre, así como de aderezar los progresivos gestos de complicidad que se dan entre ambos. Una de las escenas más significativas y en las que el tema de música incidental alcanza su mayor desarrollo e intensidad es cuando, al ir a recoger una taza, accidentalmente Aurelia provoca que el manuscrito de Jamie vuele hacia el lago. La decisión de la joven pasa por quitarse la ropa y saltar al agua en ropa interior, con la intención de recuperar los papeles. Valentía y decisión que contrastan con la actitud de Jamie, que se lanzará eminentemente por cortesía, pero vestido. Resulta en esencia significativo el primer plano que recorre todo el cuerpo de Aurelia en ropa interior bajo la mirada atenta del escritor, de forma que podríamos entender que se recurre a mostrar el cuerpo, adornado con un tatuaje, en aras de que prevalezca en el espectador la percepción de Aurelia como mujer sexualizada y en cierto modo exótica ante el de sirvienta rural, ya que a lo largo de la trama queda patente la perpetuación del rol tradicional de hombre intelectual y de elevado poder adquisitivo frente al de mujer humilde y con poca formación.

Otra de las historias atañe a un padre, Daniel, interpretado por Liam Neeson y un niño Sam interpretado por Thomas Sangster, que atraviesan un momento de duelo por la pérdida respectiva de su esposa y madre. El centro de la trama muestra la relación paternofilial entre ellos, y el acercamiento a las vivencias de amor de infancia, teniendo en cuenta que Sam se profesa enamorado de la chica popular de su colegio, Joanna, interpretada por Olivia Olson. En esta historia, la música adquiere nuevamente un papel significativo para el desarrollo de la acción, y más concretamente para la confección de roles. Dado que la niña es cantante, lo que nos sitúa una vez más en el rol de mujer históricamente aceptado como vocalista, Sam decide aprender a tocar la batería. En este sentido la batería se 
impone como la herramienta seleccionada, por un lado, para conferir a Sam, de aspecto aniñado e impopular, una planta más masculina y enérgica. Tras horas de ensayo, protagonizan junto a otros niños la función de Navidad donde ella canta sola ante el auditorio una versión del clásico «All I want for Christmas is you» de Mariah Carey. Por su parte, si bien el padre no busca ningún tipo de relación a lo largo de la película en señal de duelo, al final termina con un acercamiento casual a una mujer, Carol, interpretada por Claudia Schiffer, que deja abierta la puerta a una futura relación, como podemos ver, no con cualquier mujer.

Por otro lado, una de las historias centrales con mayor peso en el largometraje es la protagonizada por el primer ministro Hugh Grant, y su asistente, Natalie, interpretada por Martine McCutcheon. Una mujer con un cuerpo con curvas que aparece mostrado en frecuentes planos tres cuartos, de clase social media-baja, procedente de un barrio conflictivo de la capital, que utiliza un lenguaje inapropiado para trabajar en Downing Street. Pero eso es lo que parece diferenciarla dentro de un mundo plagado de convencionalismos diplomáticos y hace que el Primer Ministro la seleccione, sintiéndose atraído por esa patente naturalidad. Sin embargo, lo que desencadena el conflicto es un acoso por parte del presidente de los EE. UU. que queda retratado como un ente poderoso que a través de su influencia puede obtener absolutamente todo. El Primer Ministro interpreta la conducta como un coqueteo que desencadena en él un conflicto de celos que le lleva a tomar la decisión de trasladar su puesto de trabajo a otra parte y desplazarla lejos de él. Esta trama es la tercera que dispone de su propia partitura de música incidental: «PM’s Love Theme», de carácter institucional y presidencial que se superpone al tema portugués y sirve como vehículo en las tres persecuciones finales. Por otro lado, la música diegética en esta historia no es clave, no obstante, sí lo es para matizar la imagen más humana, menos diplomática y más divertida del propio presidente, que baila «Jump» de The Pointer Sisters por todas las dependencias presidenciales y lo que le distancia del mundo encorsetado y la diplomacia y le acerca al mundo real en el que vive Natalie. Común a estas tres últimas tramas mencionadas, en el momento álgido de la película, aderezado por el tema de música incidental «The PM's Theme», confluyen tres persecuciones, la del Primer Ministro en busca de Natalie, seguida de la de Sam en busca de Joanna en el aeropuerto y por último, la de Jamie en busca de Aurelia en el pueblo francés donde su familia portuguesa regenta un mesón. En los tres casos la acción revela el rol pasivo de la mujer y muestra cómo la iniciativa en una relación recae sobre el hombre.

Una de las historias más agridulces del largometraje que, sin duda, contribuye a la calificación de drama es la que concierne a Sarah, interpretada por Laura Lindsey y arquetipo de mujer cuidadora que trabajadora al mismo tiempo en una oficina. Dedica todo su tiempo libre a cuidar de su hermano enfermo, interno en un centro psiquiátrico con brotes violentos, al que visita diariamente y con el que habla por 
teléfono de forma muy frecuente. Su deber y su responsabilidad es el cuidado de su familiar y esto le obliga a renunciar a otras facetas de su vida sentimental. Cuando comienza una relación con uno de sus compañeros, no puede dejar de atender las llamadas caprichosas de su hermano, de tal forma que el amor a su hermano se sitúa por encima de cualquier otra relación. La música que acompaña a esta trama está muy lejos de la bucólica banda sonora que acompaña la campiña o los villancicos que resuenan a lo largo de toda la cinta. De hecho, el silencio y la repentina irrupción del reconocible tono de Nokia será la música diegética, el desencadenante que le lleva a Sarah a decidir en un corto lapso de tiempo entre ella y Karl, interpretado por Rodrigo Santoro, o ella y su hermano. Nos preguntamos si hubiera funcionado igual en el caso de que en vez de una mujer hubiera sido un hombre quien ejerciera un papel como cuidador, si fuera un hombre en la misma situación el que estuviera al cuidado de un familiar y renunciara a vivir una relación por el cuidado de aquel. En ese caso, nos preguntamos, ¿̨se entendería, funcionaría igual de bien? ¿o implícitamente tenemos muy asumido el papel de mujer como cuidadora, responsable del bienestar de los demás? Tal vez sea por ello por lo que la trama resulta triste, pero al fin y al cabo no llega a resultar chocante.

Por último, el protagonista que enmarca el comienzo y final de la película es Billy Mack, encarnado por Bill Nighy. En una película atestada de canciones populares navideñas, las versiones de música preexistente son la clave musical de toda la película. En esta línea, Billy Mack se perfila como un viejo cantante de pop, ex-heroinómano que trata de dar un nuevo impulso a su carrera en declive con la grabación de un single navideño con el que pretende ganar mucho dinero. A pesar del éxito efímero que cosecha, su vida se le revela vacía y aprecia en su manager, Joe, a su único ser querido en una relación se insinúa como un amor o cariño entre hombres por dejadez, pero no homosexual. Sin embargo, al margen de todo esto, la trama de Billy Mack nos muestra una de las escenas más sugestivas para analizar desde el punto de música y género: el videoclip correspondiente al hit navideño «Christmas is all around you». Esta será una de las pocas secuencias donde aparezcan mujeres tocando instrumentos. En este caso, se trata de un grupo de mujeres muy sexualizadas, con minivestidos de Papá Noel que rodean a un Billy Mack vestido, en cambio, íntegramente de traje. Las siete mujeres cuya denominación en el reparto figura como vixen, lo que traducido al castellano es zorra, forman la banda que acompaña a Billy, y por consiguiente aparecen tocando la batería, el bajo, la guitarra o los teclados mostrando posturas y gestos obscenos mientras fingen tocar los instrumentos (Frith y McRobbie, 1991).

En definitiva, y como conclusión, si bien Love Actually, «realmente amor», habla de que el amor está en todas partes, repara en el amor al hijo, en el amor al hermano, en el amor no correspondido, en el amor correspondido, en el amor entre personas de diferentes razas, en el amor entre personas de diferentes países 
y lenguas, en el amor entre personas de diferente clase social, de diferente escalafón, rango, en el amor maduro, en la infidelidad, en el cariño entre amigos, y sin embargo, no deja espacio alguno para el amor entre personas del mismo sexo - al parecer en el montaje definitivo se eliminó una de las tramas protagonizada por una pareja formada por dos mujeres -, en lo que podríamos interpretar como un estigma de la sociedad británica en particular y europea en general, que se muestra cosmopolita y abierta, pero al mismo tiempo, tradicional y conservadora en torno al concepto de familia. Como resultado de ello, nos encontramos con la prevalencia de la heterosexualidad normativa y homosexualidad únicamente como sospecha. Así mismo, en todas las tramas analizadas, hallamos una posición económica y laboral ventajosa para los hombres. En ese sentido, los roles asignados a las mujeres son los tradicionales como madres, cuidadoras, trabajadoras subordinadas, objetos sexuales, femme fatal, novias, amas de casa y asistentes. De hecho, el perfil de los papeles masculinos, gira en torno a los factores que han venido condicionando la masculinidad tradicional, y que son el poder adquisitivo y la solvencia económica, la formación académica, la heterosexualidad, el rol secundario en el hogar y los altos cargos laborales.

Quince años después de su lanzamiento nos preguntamos qué consecuencias ha podido tener, tiene o podría tener en el futuro la visualización del filme. Teniendo en cuenta que un target predominante al que va dirigida esta clase de películas son mujeres, sería conveniente promover una visualización crítica y entendida desde la evolución de la sociedad en políticas y cultura de género. Sin embargo, al igual que sucede con otras películas del género romance, el cine es un crisol de la sociedad y en muchas ocasiones un reflejo real de lo que sucede. ¿Pueden tener consecuencias en la percepción de los roles sociales de género de quien lo observa? ¿El público es consciente de los mensajes que recibe? ¿Cuáles son esos mensajes? ¿Se corre el riesgo de que de forma inocente y sutil la película siga avivando el asentamiento de los roles de género tradicionales? ¿Cuál es el mensaje ético y moral que nos transmite? En primer lugar, que la mujer transige y se sacrifica. Que sobre ella recae el peso de la responsabilidad familiar como madre, esposa y cuidadora, pero también la responsabilidad en las infidelidades. Mientras que por su parte, sobre el hombre recae el peso de la responsabilidad laboral, económica y política. Que el cuerpo de la mujer es un objeto de reclamo que puede utilizarse como aderezo o como adorno meramente visual, mientras que en muy contadas ocasiones se hace lo propio con el del hombre.

¿Significa que la mujer y el hombre espectadores se sienten cómodos viendo a otras mujeres y hombres desempeñando estos papeles? ¿Cuáles son las claves para que un guion desigualitario siga funcionando y que el mensaje en torno a los roles de género se perciba con suma sutileza? Bajo nuestro punto de vista podemos hablar de varios factores paralelos entre los que sobresale la prestigiosa selección 
del reparto con una o varias celebridades en cada historia paralela, a lo que sin duda corresponde atribuir el crédito y popularidad de la producción. Pero en este proceso no resulta menos importante la rapidez de las tramas, que transcurren y evolucionan sin solución de continuidad y favorecen un visionado de la película con un ritmo intrépido y sin espacios para el silencio, la dispersión y la reflexión. En ella todo se sucede a gran velocidad con lo que la finalidad parece estar en una percepción holística y no en una percepción fragmentada y anecdótica. En segundo lugar, no podemos dejar de mencionar el humor inglés y la presencia de ingredientes cómicos en prácticamente todas las tramas que actúa como filtro de estos tópicos y a la vez ornamenta el desarrollo de las tramas en un ambiente amable. Por último, bajo nuestro punto de vista, a lo largo del largometraje de Love Actually, la música actúa como cómplice de la perpetuación de los roles de género tradicionales, dado que a lo largo de las tramas actúa como bisagra y en muchos casos apela a la emoción fácil y ampulosa en el espectador.

La música está presente de forma continua tanto en su forma diegética como incidental. En numerosas ocasiones podemos percibir la fuente en momentos clave de las subtramas. Ejemplo de ello es el cedé como prueba de la infidelidad que hará tambalearse el bienestar familiar, al tiempo que remarca por un lado a la mujer madura, centrada en un crecimiento espiritual, que debe transigir, y por otro a la mujer joven y codiciosa preocupada por su belleza, a quien se señala como culpable del conflicto. También el tono de Nokia de las llamadas del hermano de Sarah. A lo largo del mismo Sarah debe tomar una decisión y decidir un camino en el que la prioridad sean sus propios deseos o el cuidado de su hermano, sin que parezca que pueda haber un punto intermedio. La función musical navideña donde el niño se estrena como estrella del rock y la niña deja boquiabierto al auditorio con su voz, es la prueba de oro para conseguir a la chica. Y por otro lado, también al respecto de la música diegética podemos observar la interpretación musical los roles de género tradicionales. Los instrumentos que aparecen en la película son interpretados por hombres en su gran mayoría (Ramos, 2003). Tan solo hay tres excepciones, el cuarteto de la boda, las mujeres como vocalistas en los coros y las mujeres como instrumentistas de la banda de Rock de Billy Mack, en cuyo caso su papel como instrumentistas es ridiculizado y su aparición responde a un mero objeto ornamental y sexualizado. Por último, respecto a la música incidental me gustaría reparar en la trama final, donde se desarrolla el tema del Primer Ministro. En ella se superponen tres persecuciones, el Primer Ministro en busca de Natalie, Sam en busca de Joanna y Jamie en busca de Aurelia. Lo que incentiva el rol de hombre activo y mujer pasiva, a la espera de los pasos y las acciones ejecutadas por él.

En definitiva, en todos los amores, en todas las historias, la música ejerce una función determinante, ya sea como eje de conflicto, como punto de inflexión, de 
BEATRIZ HERNÁNDEZ POLO

LOVE ACTUALLY Y LA ESFERA MUSICAL COMO CÓMPLICE DE LA PERPETUACIÓN DE LOS ROLES DE GÉNERO TRADICIONALES

acercamiento, de desenlace. Aparece en su forma diegética constantemente en algunas de las historias, y sin embargo en otras en su forma incidental, contextualizando o bien enfatizando la trama emocional, y de una u otra forma, la música se presenta a lo largo de toda la cinta como un referente claramente significativo, a la hora de llevar a cabo una lectura desde la perspectiva de género. A lo largo de este artículo no pretendemos denunciar el tratamiento de roles, sino visibilizarlos y plantear la necesidad imperante de ser conscientes de lo que estamos viendo y consumiendo. El peligro de que con un envoltorio dulce demos por óptimo lo que puede ser una normalización de roles que no representan la realidad igualitaria a la que la sociedad occidental parece que quiere aspirar.

\section{REFERENCIAS BIBLIOGRÁFICAS}

Arranz, F. (dir.). (2010). Cine y género en España. Madrid: Cátedra. Feminismos.

Ashby, J. (2005). Postfeminism in the British Frame. Cinema Journal, 44, 2, 127-132.

Basinger, J. (1993). A Woman's View: How Hollywood Spoke to Women, 1930-1960. Middletown: Wesleyan University Press.

Belinchón, G. (2017). Por la igualdad de género en el cine. El País, 14-6-2017. Recuperado de: https://elpais.com/cultura/2017/06/13/actualidad/1497354488_189998.html.

Brett, P. et al. (1994). Queering the Pitch. The new gay and lesbian musicology. New York: Routledge.

Brown, M. (2017). British cinema's gender imbalance worse in 2017 than 1913, says BFI study. The Guardian, 20-09-2017. Recuperado de: https://wwro.theguardian.com/ film/2017/sep/20/british-cinema-gender-imbalance-worse-2017-bfi-filmography.

Butler, J. (1991). Gender Trouble: Feminism and the subversion of Identity. New York: Routledge.

Citron, M. J. (1993). Gender and the musical canon. Cambridge: Cambridge University Press.

Clément, C. (1988). Opera or the Undoing of Women. Minneapolis: Minnesota University Press.

Cohan, S. y Hark, I. R. (Eds.). (1992). Screening the male: exploring masculinities in the Hollywood cinema. London: Routledge.

Filardi, E. (2015). Todo lo que necesitas saber sobre la vida está en Love Actually. Recuperado de: http://www.jotdown.es/2015/05/todo-lo-que-necesitas-saber-sobrela-vida-esta-en-love-actually/.

Frith, S. y McRobbie, A. (1991). Rock and sexuality. En S. Frith y A. Goodwin (Eds.), On Record: Rock, Pop and the Written Word (pp. 371-389). London \& New York: Routledge.

Kaplan, A. (1983). Women and Film: Both sides of the Camera. New York \& London: Methuen. 
BEATRIZ HERNÁNDEZ POLO

LOVE ACTUALLY Y LA ESFERA MUSICAL COMO CÓMPLICE DE LA PERPETUACIÓN DE LOS ROLES DE GÉNERO TRADICIONALES

Laguarda, P. (2006). Cine y estudios de género: Imagen, representación e ideología. Notas para un abordaje crítico. Revista Aljaba, 10, 141-156.

McClary, S. (1991). Feminine Endings. Music, gender and sexuality. Minneapolis: University of Minnesota Press.

McRobbie, A. (2007). «Postfeminism and Popular Culture: Bridget Jones and the New Gender Regime». En Y. Tasker y D. Negra (Eds.), Interrogating Postfeminism (pp. 255-264). Durham: Duke University Press.

Murphy, J. N. (2015). The role of women in film: Supporting the men. An analysis of how culture influences the changing discourse on gender representations in film. Journalism Undergraduate Honors Theses, 2.

M. V. (2017). ¿Y si Love Actually no fuese la encantadora película que siempre creímos? La voz de Galicia, 19-12-2017. Recuperado de: https://www.lavozdegalicia.es/ noticia/cultura/2017/12/19/love-actually-fuese-encantadora-pelicula-siemprecreimosera/00031513698552435743320.htm.

Powrie, P. (2004). The trouble with men: masculinities in European and Hollywood cinema. New York: Columbia UP.

Quick, M. (2018). The data that reveals the film industry's 'woman problem'. $B B C$, 9-5-2018. Recuperado de: http://www.bbc.com/culture/story/20180508-the-datathat-reveals-the-film-industrys-woman-problem.

Ramos, P. (2003). Feminismo y música. Introducción crítica. Madrid: Narcea Ediciones.

Salam, M. (2018). Hollywood Is as White, Straight and Male as Ever. The New York Times, 2-8-2018. Recuperado de: https://www.nytimes.com/2018/08/02/arts/hollywoodmovies-diversity.html.

Scharaga, J. A. (2017). Female Moments / Male Structures: The Representation of Women in Romantic Comedies. Media and Communication Studies Honors Papers, 6.

Solie, R. A. (Ed.). (1993). Musicology and Difference: Gender and Sexuality in Music Scholarship. Berkley: University of California Press.

Viñuela, L. (2003). La perspectiva de género y la música popular: dos nuevos retos para la musicología. Oviedo: KRK Ediciones. 